\title{
A experimentação como método inovador para o ensino de ciências: estudo realizado com uma turma do curso de pedagogia
}

The experimentation as innovative method for science teaching: the study with pedagogy course class

\author{
P. A. P. F. G. das Neves ${ }^{1 *}$; M. D. de B. Silva ${ }^{2}$; S. M. Vasconcelos 3 ; S. C. de J. da
} Silva $^{4}$; N. N. da Hora ${ }^{5}$

${ }^{I}$ Mestre em Ciências Ambientais (UEPA). Doutorando do Programa de Pós-Graduação Biodiversidade e Biotecnologia da Amazônia Legal (PPG-BIONORTE), Belém-Pará, Brasil.

${ }^{2}$ Mestra em Química (UFPA). Docente do Curso de Licenciatura Plena em Ciências Naturais da Universidade do Estado do Pará (UEPA)

${ }^{3}$ Doutora em Educação (PUC-RJ). Docente do Curso de Licenciatura Plena em Ciências Naturais da Universidade do Estado do Pará (UEPA)

${ }^{4}$ Mestra em Ciências Ambientais (UEPA). Professora do Plano Nacional de Formação de Professores- PARFOR pela Universidade do Estado do Pará, Campus de Santarém. Professora de Ciências no município de Parauapebas-Pará, Brasil.

${ }^{5}$ Mestra em Ciências Ambientais (UEPA). Doutoranda do Programa de Pós-Graduação Sociedade, Natureza e Desenvolvimento da Universidade Federal do Oeste do Pará (UFOPA), Santarém-Pará, Brasil.

*paulo.panarra@gmail.com

(Recebido em 26 de março de 2016; aceito em 17 de abril de 2016)

O objetivo deste trabalho foi desenvolver experimentos voltados para o ensino de Ciências - Ensino Fundamental I, tendo em pauta a identificação das dificuldades encontradas pelos professores em utilizar a experimentação como metodologia de ensino em suas aulas de ciências, proporcionando uma análise sobre a disciplina da Química e Metodologia do Ensino de Ciências para sua atuação profissional. Tratou-se de um estudo de abordagem qualitativo-quantitativo, do tipo exploratório. A pesquisa foi realizada durante a disciplina Química e Metodologia do Ensino de Ciências, tendo como participantes 18 graduandos do $5^{\circ}$ semestre do Curso de Licenciatura Plena em Pedagogia da Universidade do Estado do Pará (UEPA), este curso é ofertado por meio do Plano Nacional de Formação de Professores da Educação Básica (Parfor). A partir dos resultados obtidos, verificou-se que a formação voltada para conteúdo específicos no Ensino Superior voltado para a preparação do professor polivalente se faz necessária, porém a inclusão de disciplinas de conteúdo específico não pode estar dissociada da metodologia de ensino.

Palavras-chave: Ensino de Ciências, Experimentação, PARFOR

Objective of this study was to develop experiments directed for science teaching in basic education Elementary School I, in order to identify the difficulties encountered by teachers to use the experimentation as a teaching Metodology in their science classes, providing an analysis of the chemical methodology of science education for their professional work. It s a study of qualitative and quantitative approach, an exploratory. The research was realized during the chemistry class and methodology of science teaching, with participating 18 students from the 5th semester of Full Degree in Pedagogy of "Universidade do Estado do Pará (UEPA)", this course is offered through the "Plano Nacional de Formação de Professores da Educação Básica (Parfor)". From the results, was identified that focused training for specific content in undergraduation focused on the preparation of polyvalent teacher is necessary, but the inclusion of contentspecific disciplines can not be dissociated from the teaching methodology.

Keywords: Science Tecahing, Experimentation, PARFOR 


\section{INTRODUÇÃO}

No período de 1950 a 1970, o Brasil passou por um momento em que sua economia crescia de forma acelerada devido à entrada do capital estrangeiro atraído principalmente pelas baixas taxas de impostos [1].

Criou-se um ambiente favorável à racionalização da Educação e à implementação de uma tecnologia educacional capaz de responder às exigências do mercado, ao passo que se produzia a despolitização das práticas [1].

O pensamento educacional se voltou para a instrumentalização do ensino e a formação docente passou a ser orientada para o domínio de comportamentos e habilidades passíveis de serem observados e verificados [2].

As questões relativas à formação de professores para educação básica, de forma específica, se configuraram, a partir dos anos 1990, como um dos principais pontos de atuação das políticas educacionais brasileiras [3].

Em 1996 foi criada a Lei de Diretrizes e Bases da Educação Nacional (LDB nº 9394), que definiu os níveis de qualificação para atuação docente na Educação Básica. Nesta lei é ressaltada a importância da Formação Continuada, incluindo o acesso aos cursos de mestrado e doutorado:

II - formar diplomados nas diferentes áreas de conhecimento, aptos para a inserção em setores profissionais e para a participação no desenvolvimento da sociedade brasileira, e colaborar na sua formação contínua (art. 43); III - programas de educação continuada para os profissionais de educação dos diversos níveis (art. 63); II aperfeiçoamento profissional continuado, inclusive com licenciamento periódico remunerado para esse fim (art. 67) [4].

A Rede Nacional de Formação Continuada de Professores da Educação Básica, publicado no ano de 2005 pelo Ministério da Educação [5], ressalta no item 2, página 14 (Base legal para institucionalização da Formação Continuada) outras leis que incentivam a formação continuada:

A Lei $n^{\circ}$ 9424/96 que instituiu o FUNDEF estabelece que $60 \%$ dos recursos do Fundo sejam destinados à remuneração do magistério, sendo que a parcela restante (de até $40 \%$ ) deve ser aplicada em ações variadas, de manutenção e desenvolvimento do ensino fundamental público, dentre as quais a formação (inicial e continuada) dos professores e a capacitação de pessoal técnico-administrativo.

De igual modo, a Resolução $\mathrm{n}^{\circ}$ 03/97, do Conselho Nacional de Educação, definiu, no artigo $5^{\circ}$, que os sistemas de ensino "envidarão esforços para implementar programas de desenvolvimento profissional dos docentes em exercício, incluída a formação em nível superior em instituições credenciadas, bem como, em programas de aperfeiçoamento em serviço". Desse modo, os planos de carreira devem incentivar a progressão, por meio da qualificação inicial e continuada dos trabalhadores da educação.

Por sua vez, o Plano Nacional de Educação - PNE- (Lei n.10.172/2001), ao estabelecer os objetivos e metas para a formação inicial e continuada dos professores e demais servidores da educação, enfatiza que se faz necessário criar programas articulados entre as instituições públicas de ensino superior e as secretarias de educação, de modo a elevar o "padrão mínimo de qualidade de ensino". 
O ensino de Ciências para as séries iniciais possui algumas particularidades quando comparada as séries subsequentes. Sua principal característica é o fato de ser praticada por um professor polivalente, em geral responsável também pelo ensino de outras disciplinas [6].

De acordo com Bonando [7], o ensino de Ciências Naturais tem sido desenvolvido de forma precária, em muitos casos há predominância de métodos de ensino ultrapassados, como por exemplo, a transcrição no quadro de listas de exercícios para as crianças estudarem para as provas, ocasionando a decoração de conceitos em detrimento do entendimento dos conceitos estudados.

Os Parâmetros Curriculares Nacionais (PCN) destacam a importância de ensinar conteúdos deste componente desde as primeiras séries do ensino básico [8]. Segundo Ovigli; Bertucci, (2009) [6], através do ensino de Ciências é possível promover a alfabetização científica durante as séries iniciais, de modo que o aluno possa refletir de forma crítica sobre o conhecimento científico a fim de realizar leituras de seu cotidiano.

Em 2009, foi instituída a Política Nacional de Formação de Profissionais do Magistério da Educação Básica, através do decreto $n^{\circ}$ 6755. Esta política disciplina a atuação da Coordenação de Aperfeiçoamento de Pessoal de Nível Superior (CAPES) no fomento a programas de formação inicial e continuada [9].

O Plano Nacional de Formação de Professores da Educação Básica (Parfor) é um plano de caráter emergencial, que visa assegurar a formação exigida na LDBEN para professores que atuam na rede pública, oferecendo gratuitamente cursos superiores [10].

O Parfor fomenta a oferta de turmas especiais em cursos de:

I. Licenciatura - para docentes ou tradutores intérpretes de Libras em exercício na rede pública da educação básica que não tenham formação superior ou que mesmo tendo essa formação se disponham a realizar curso de licenciatura na etapa/disciplina em que atua em sala de aula;

II. Segunda licenciatura - para professores licenciados que estejam em exercício há pelo menos três anos na rede pública de educação básica e que atuem em área distinta da sua formação inicial, ou para profissionais licenciados que atuam como tradutor intérprete de Libras na rede pública de Educação Básica; e III. Formação pedagógica - para docentes ou tradutores intérpretes de Libras graduados não licenciados que se encontram no exercício da docência na rede pública da educação básica [11].

De acordo com dados da CAPES, até o ano de 2014 foram implantadas 2.428 turmas, em 451 municípios, localizados em 24 unidades da federação. Em 2015, eram 51.008 professores da Educação Básica frequentando os cursos do Programa Nacional de Formação de Professores Parfor e 12.103 professores já concluíram sua formação.

No Curso de Licenciatura Plena em Pedagogia do Programa Nacional de Formação de Professores Parfor da Universidade do Estado do Pará (UEPA) é ofertada a disciplina Química e Metodologia do Ensino de Ciências, a qual teve uma abordagem inovadora ao privilegiar, entre outros aspectos, a experimentação para o ensino de Ciências.

A disciplina apresenta grande potencial na contribuição de uma formação diferenciada em Ciências para os professores das séries iniciais do Ensino Fundamental e Educação Infantil, e promover mudanças em suas práticas pedagógicas.

Pelo potencial de formação dessa disciplina, ela tornou-se o foco da presente pesquisa, desta forma o presente trabalho objetivou desenvolver experimentos voltados para o ensino de Ciências - Ensino Fundamental I, tendo em pauta a identificação das dificuldades encontradas pelos professores em utilizar a experimentação como metodologia de ensino em suas aulas de ciências, proporcionando uma análise sobre a da disciplina Química e Metodologia do Ensino de Ciências para sua atuação profissional. 


\section{MATERIAL E MÉTODOS}

Este estudo apresentou uma abordagem qualitativo-quantitativo, do tipo exploratório. De acordo com Silveira; Córdova [12], a investigação quantitativa tende a enfatizar o raciocínio dedutivo, as regras da lógica e os atributos mensuráveis da experiência humana. A investigação qualitativa tende a salientar os aspectos dinâmicos, holísticos e individuais da experiência humana, para apreender a totalidade no contexto daqueles que estão vivenciando o fenômeno.

A pesquisa foi realizada durante a disciplina Química e Metodologia do Ensino de Ciências, tendo como participantes 18 graduandos do $5^{\circ}$ semestre do Curso de Licenciatura Plena em Pedagogia da UEPA, este curso foi ofertado por meio do Programa Nacional de Formação de Professores - Parfor.

Um dos objetivos desta disciplina foi apresentar aos graduandos metodologias para o ensino de Ciências. Durante as aulas foi enfatizada a experimentação, visto que este método de ensino foi o que mais chamou a atenção dos graduandos.

Durante a disciplina foi proposto que a turma fosse dividida em grupos e cada grupo apresentasse 02 (dois) experimentos, totalizando 10 experimentos (Quadro 1). Todos os experimentos foram executados com materiais de baixo custo.

Vale ressaltar que os experimentos foram selecionados pelos graduandos, não houve nenhum manual e/ou livro para seleção dos experimentos.

Tabela 1: Experimentos utilizados

\begin{tabular}{|c|c|c|c|}
\hline $\mathbf{N}^{\mathbf{o}}$ & Experimento & Materiais utilizados & Assunto \\
\hline 1 & $\begin{array}{l}\text { Balão que não } \\
\text { estoura }\end{array}$ & Balão, vela, pires e fósforo. & $\begin{array}{l}\text { Capacidade calorífica do } \\
\text { ar e da água }\end{array}$ \\
\hline 2 & Garrafa chuveirinho & Garrafa, prego, água e tigela. & Pressão atmosférica \\
\hline 3 & $\begin{array}{l}\text { Identificando amido } \\
\text { em alimentos }\end{array}$ & Tintura de iodo, pires e alimentos. & Amido nos alimentos \\
\hline 4 & $\begin{array}{l}\text { Pressão atmosférica } \\
\text { no copo }\end{array}$ & Copo, água e papel. & Pressão da água e do ar \\
\hline 5 & Eletrização por atrito & $\begin{array}{l}\text { Canudo, papel e lata de } \\
\text { refrigerante. }\end{array}$ & Eletrização por atrito \\
\hline 6 & Combustão no copo & Copo, vela, prato e água. & Consumo de oxigênio \\
\hline 7 & Propriedades da água & Copo, água, corante, essência. & Propriedades da água \\
\hline 8 & O ar possui peso? & Balão, fio e vareta. & Ar atmosférico \\
\hline 9 & $\begin{array}{l}\text { O balão que não } \\
\text { estoura }\end{array}$ & Balão, óleo e agulha. & $\begin{array}{l}\text { Propriedades das cadeias } \\
\text { poliméricas }\end{array}$ \\
\hline 10 & Camadas de líquidos & $\begin{array}{l}\text { Tubo cilíndrico alto e transparente, } \\
\text { xarope de milho ou mel, água com } \\
\text { algumas gotas de corante, álcool } \\
\text { com algumas gotas de corante de } \\
\text { outra cor, óleo vegetal e objetos } \\
\text { como: bolinha de metal ou de } \\
\text { gude. }\end{array}$ & Solubilidade e densidade \\
\hline
\end{tabular}

Para obtenção dos resultados foi aplicado um questionário organizado em duas partes: dados gerais (gênero, faixa etária, nível de formação e tempo de atuação como docente) e 06 (seis) questões discursivas sobre a experimentação no ensino de Ciências. As respostas dos participantes da pesquisa foram identificadas pela letra $P$.

Para que os participantes respondessem o questionário utilizado neste trabalho, foi realizada uma breve explanação sobre os objetivos da pesquisa a fim de colocar todos os acadêmicos a par do assunto e de sua importância, e também a necessidade da assinatura do Termo de Consentimento Livre-Esclarecido (TCLE). 


\section{RESULTADOS E DISCUSSÃO}

Quanto ao perfil dos 18 graduandos, verificou-se que 95,5\% são do sexo feminino e 4,5\% do sexo masculino. Em relação à faixa etária, constatou-se que 5,5\% apresentam idade entre 20 a 30 anos; $16,5 \%$ entre 30 a 40 anos; $16,5 \%$ e 50 anos e $61,5 \%$ acima de 50 anos. Esses resultados corroboram em relação ao gênero e diferem em relação a idade com os resultados encontrados por Melo (2013) [13].

Em relação à formação, constatou-se que $67,0 \%$ possuem formação de magistério; $16,5 \%$ graduação; $11 \%$ especialização e 5,5\% não responderam. Quanto ao tempo de atuação como docente do Ensino Básico, 28,0\% apresentam entre 5-10 anos de experiência; 22,0\% entre 16 a 20 anos; $22,0 \%$ entre 21 a 25 anos; $17 \%$ entre 26 a 30 anos e $11 \%$ possui mais de 30 anos de atuação.

Quando questionados sobre a utilização da experimentação durante as aulas de Ciências, verificou-se que $78 \%$ afirmaram usar experimentos, porém os mesmos limitam-se aos conceitos físicos e biológicos, em detrimento dos conceitos químicos. Os demais (22\%) não fazem uso da experimentação nas suas aulas.

Através dos experimentos citados pelos graduandos, os temas contemplados são: ar atmosférico (26\%), desenvolvimento do pé de feijão (24\%), estados físicos da água (20\%), transmissão do calor (10\%), eletrização por atrito (10\%), reciclagem $(5 \%)$ e sistema sensorial $(5 \%)$.

Tal resultado é reflexo de uma tradição curricular que se instituiu historicamente na área de Ciências, caracterizada por uma forte centralidade na perspectiva biológica de abordagem dos conteúdos escolares e de uma formação deficiente em química [14].

Em relação às dificuldades enfrentadas para o desenvolvimento de atividades experimentais, $33,5 \%$ dos entrevistados afirmaram que a falta de Programas de Formação Continuada na área de Ciências como um fator limitante; $22 \%$ citaram a falta de materiais; $16,5 \%$ responderam a falta de planejamento e a reduzida carga horária para a disciplina de Ciências; $11 \%$ informaram a participação dos alunos, os demais (17\%) afirmaram não possuir nenhuma dificuldade.

Tal realidade também foi encontrada por Ramos; Rosa [15]:

Assim, além de esclarecerem que são poucas as vezes que desenvolvem atividades experimentais, algumas professoras também apontaram algumas dificuldades que encontram para trabalhar com esse tipo de atividade, tais como: pequena quantidade de material, ausência de um local adequado e falta de preparo para lidar com esse tipo de situação [15].

Através deste resultado, nota-se que o principal fator é a carência de Programas de Formação Continuada voltada para o ensino de Ciências, visto que o Pacto Nacional pela Alfabetização na Idade Certa (PNAIC) direcionado aos professores das séries iniciais preconiza a formação continuada para as disciplinas de português e matemática, tal característica é evidenciada na resposta de um participante da pesquisa:

“A principal dificuldade seria a falta de formação continuada na área de Ciências, pois em geral as mesmas se restringem a Língua Portuguesa e Matemática" (P1).

O PNAIC constitui um conjunto integrado de ações, materiais e referências curriculares e pedagógicas disponibilizados pelo Ministério da Educação (MEC), tendo como eixo principal a formação continuada de professores alfabetizadores [16]. Os objetivos deste pacto nacional são:

I - garantir que todos os estudantes dos sistemas públicos de ensino estejam alfabetizados, em Língua Portuguesa e em Matemática, até o final do $3^{\circ}$ ano do ensino fundamental; II - reduzir a distorção idade-série na Educação Básica; 
III - melhorar o Índice de Desenvolvimento da Educação Básica (IDEB);

IV - contribuir para o aperfeiçoamento da formação dos professores alfabetizadores;

V - construir propostas para a definição dos direitos de aprendizagem e desenvolvimento das crianças nos três primeiros anos do ensino fundamental [17].

O reflexo do PNAIC em relação às Ciências Naturais é negativo, visto que o é destinado maior carga horária para as disciplinas de Português e Matemática. Essa situação soma-se às demais dificuldades específicas ao ensino desses conhecimentos nessa fase da escolarização, podendo significar um retrocesso às escolas de ler e escrever, presentes por tanto tempo na história da educação brasileira [18].

A modernização dos meios de comunicação e transporte proporcionou ao mundo uma maior integração e diminuiu de forma drástica a relação tempo $\mathrm{x}$ espaço, proporcionando um maior fluxo de informação e pessoas no mundo todo. Além dos avanços nos meios de informações e locomoção, também houve um crescimento das universidades e como consequência uma maior produção de conhecimento científico, fazendo com que os professores estejam atualizados para que possam corresponder a necessidade dos seus alunos e da sociedade em geral.

Para Rebelo; Martins; Pedrosa [19]:

Nas sociedades ocidentais, cada vez mais se vem constatando a integração e interdependência sociocultural e econômica, com reflexos nas linguagens dos próprios movimentos de reforma educativa, em que se reconhecem lógicas da globalização atual que, apoiando-se em políticas econômicas e modelos de gestão neoliberais, reguladas e controladas por princípios neoconservadores, celebram a produtividade, a competitividade e o lucro [19].

Com relação a avaliação dos experimentos apresentados em sala pelos grupos em sala de aula, verificou-se que $100 \%$ dos graduandos afirmaram que a experimentação é uma metodologia inovadora para o ensino e que pode ser desenvolvida durante as aulas de Ciências com materiais de baixo custo.

Quando questionados sobre o experimento que mais chamou atenção, obteve-se como resposta: $39 \%$ o experimento da garrafa chuveirinho, 33,5\% identificando carboidrato nos alimentos, $16,5 \%$ agulha no balão e $11 \%$ canudo com a lata de refrigerante.

A realização de experimentos, em Ciências, representa uma excelente ferramenta para que o aluno faça a experimentação do conteúdo e possa estabelecer a dinâmica e indissociável relação entre teoria e prática [20].

O PCN ressalta que as atividades não se limitem a nomeações e manipulações de vidrarias e reagentes, fora do contexto experimental. É fundamental que as atividades práticas tenham garantido o espaço de reflexão, desenvolvimento e construção de ideias, ao lado de conhecimentos de procedimentos e atitudes [18].

Após a apresentação dos experimentos, os mesmos foram questionados se estavam preparados para desenvolvê-los durante as aulas de Ciências, constatou-se que $100 \%$ dos participantes afirmaram que se sentem seguros para utilizar a experimentação durante as aulas de Ciências, como pode ser identificado nas respostas:

"Sim, pois aprendi vários conceitos com os experimentos apresentados pelos colegas" ( $\mathrm{P} 2)$.

"Sim, pois sabemos que os erros também fazem parte e podem ser discutidos em sala de aula" (P3). 
Através deste resultado, verifica-se a necessidade de programas voltados para a Formação Inicial e Continuada dos Professores, visto que após a execução dos experimentos em sala de aula os mesmos sentiram-se seguros para a utilização desta metodologia durante as aulas de Ciências.

De acordo com Silva [21], através de Programas de Formação Continuada é possível ocasionar diversas mudanças:

[...] traz mudanças no fazer pedagógico do professor, bem como na cultura escolar. Novas práticas de gestão e participação democrática são desenhadas. A formação continuada na escola pode constituir-se, a partir do cotidiano profissional, um fazer de pesquisa e formação, com reflexão individual e coletiva sobre suas práticas, mantendo relações com outros formadores que possam ajudá-los a ressignificar suas práticas e teorias.

Quando questionados aos graduandos qual visão da disciplina Química antes de cursar a disciplina "Química e Metodologia do Ensino de Ciências". Sobre esta pergunta, todos os participantes apresentavam uma visão limitada, pois em suas respostas foram mencionados cálculos, fórmulas e também tinham a ideia que esta disciplina somente era possível ser desenvolvida em laboratório, como demonstram as respostas:

"Acredito que era uma visão limitada, pois concebia a Química como resumida a cálculos matemáticos e específicos a laboratórios" (P4).

"De que a disciplina era de dificil acesso nas séries iniciais" (P5).

"Era de muitos cálculos como no ensino médio" (P6).

"Uma disciplina com conteúdos fora do meu cotidiano, com muitos cálculos e de dificil compreensão" (P7).

"Uma disciplina com muitos cálculos" (P8).

Tais respostas demonstram a formação deficiente que os graduandos receberam durante a sua Formação Inicial. Este aspecto é destacado por Ducatti-Silva [22], o qual afirma que o professor termina o curso de Magistério e a Licenciatura em Pedagogia, geralmente sem a formação adequada para ensinar Ciências Naturais.

Desse modo, sua prática pedagógica, influenciada diretamente pela formação precária que teve nessa área, é evidenciada em aulas teóricas totalmente desvinculadas da vivência cotidiana dos alunos [6].

Por fim, os participantes da pesquisa foram questionados sobre a contribuição da disciplina Química e Metodologia do Ensino de Ciências para sua atuação profissional. Destaca-se que $100 \%$ afirmaram que a disciplina contribuiu de maneira significativa para a melhoria da prática docente, como podem ser observadas pelas respostas abaixo:

"Foi muito importante, pois fica claro que os experimentos não são apenas para atingir um fim, mas principalmente para despertar o interesse dos alunos para descoberta de novos conhecimentos." (P9).

"Essa disciplina nos mostrou que somos capazes de desenvolver nossas aulas dessa maneira também. Agora tenho certeza que irei modificar mais ainda minha prática pedagógica aproveitando as experiências que tivemos durante a disciplina, e adaptar para meus alunos." (P10).

"Essa disciplina vai contribuir bastante para as práticas experimentais durante as aulas de ciências, pois irá proporcionar uma aula diferenciada e prazerosa." (P11). 
De acordo com Silva; Bastos [23]:

Em síntese, (re)pensar/discutir a formação docente para o Ensino de Ciências significa perceber que a valorização do conhecimento científico e tecnológico pela sociedade contemporânea exige do professor a realização de um trabalho que rompa com os conceitos que lidam com as Ciências de forma dogmática, acrítica e descontextualizada da realidade global, a fim de que ele possa contribuir para a formação de cidadãos críticos, alfabetizados cientificamente.

A Formação Continuada proporciona ao professor novos conhecimentos, que auxiliam o mesmo a adquirir uma postura ativa no processo ensino aprendizagem, ou seja, o professor não será apenas transmissor de um conhecimento para seus alunos, pelo contrário o mesmo terá capacidade em tornar o aluno ativo no processo ensino aprendizagem.

Nesta perspectiva, é importante considerar, também, que o conhecimento não pode ser passado do professor para o aluno de forma passiva, sendo importante valorizar a visão de um envolvimento interativo num processo em que tanto quem ensina seja ativo, nas relações pedagógicas não simétricas [24].

\section{CONSIDERAÇÕES FINAIS}

A partir dos resultados obtidos, verifica-se que a o Parfor tem contribuído para a melhoria da Formação de Professores da Educação Básica, visto que no desenho curricular há disciplinas que proporcionam a construção do conhecimento de maneira interdisciplinar, como é o caso da disciplina Química e Metodologia do Ensino de Ciências no Curso de Licenciatura Plena em pedagogia.

Diante do exposto, verifica-se que através da experimentação foi possível mostrar aos graduandos que os mesmos são capazes de desenvolver aulas experimentais nas escolas que atuam o que possibilita mudança da prática pedagógica deste professor em sala de aula. Também se observou uma mudança na visão que os graduandos possuíam da disciplina Química, o que traz grandes avanços para o processo ensino aprendizagem, pois através deste programa de formação, os mesmos estão recebendo informações que possibilitam a inserção dos fenômenos vivenciados no cotidiano nos conteúdos estudados em sala de aula.

Espera-se que o ensino de Ciências Naturais nos anos iniciais do Ensino Fundamental seja ministrado de maneira que interaja com outras disciplinas do desenho curricular, e consequentemente aproximando os assuntos estudados em sala de aula para a realidade de vida do aluno, através de metodologias inovadoras para o ensino, como por exemplo, a experimentação.

\section{REFERÊNCIAS BIBLIOGRÁFICAS}

1. Alves WF. A formação de professores e as teorias do saber docente: contextos, dúvidas e desafios. Educação e Pesquisa. 2007 maio/ago: 33(2): 263-280.

2. Lelis IA. Do ensino dos conteúdos aos saberes do professor: mudança de idioma pedagógico? Educação \& Sociedade. 2001. abril: ano XXII, n. 74: 43-58.

3. Souza VC. Política de formação de professores para a educação básica: a questão da igualdade. Rev. Bras. Educ. 2014 jul/set: 19(58): 629 - 653, doi.org/10.1590/S1413-24782014000800006.

4. Ministério da Educação (BR). Lei de Diretrizes e Bases da Educação Nacional. Brasília (DF): Ministério da Educação; 1996.

5. Ministério da Educação (BR). Rede Nacional de Formação Continuada de Professores de Educação Básica. Brasília (DF): Ministério da Educação; 2005.

6. Ovilgi DFB; Bertucci, MCS. A formação para o ensino de ciências naturais nos currículos de pedagogia das instituições públicas de ensino superior paulistas. Ciências \& Cognição. 2009: 14 (2): 194-209. 
7. Bonando PA. Ensino de Ciências nas séries iniciais do $1^{\circ}$ grau - descrição e análise de um programa de ensino e assessoria ao professor [dissertação] São Carlos (SP); 1994.

8. Ministério da Educação (BR). Parâmetros Curriculares Nacionais: Ciências Naturais. Brasília (DF): Ministério da Educação; 1998.

9. Ministério da Educação (BR). Decreto n ${ }^{\circ} 6.755$, de 29 de Janeiro de 2009. Brasília (DF): Ministério da Educação; 2009.

10. Abdalla MFB; Martins MAR; Silva AFL. Representações sociais em movimento: professoresestudantes em Curso de Pedagogia do Parfor. Educação \& Linguagem. 2012: 5(25): 83 - 103, doi.org/10.15603/2176-1043/el.v15n25p83-103.

11. Plano Nacional de Formação de Professores da Educação Básica - PARFOR [internet]. Brasília; 2010.[acesso em 2014 jul 10] Disponível em: http://www.capes.gov.br/educacaobasica/parfor

12. Silveira DT; Córdova FP. A pesquisa científica. In: Gerhardt TE; Silveira DT. Métodos de pesquisa. Porto Alegre: Editora da UFRGS, 2009.

13. Melo SG. Representações sociais sobre a cidadania ambiental: o que pensam os professoresestudantes do parfor. Pesquisa em Pós-Graduação. 2013: Série Educação, n.8: 47-54.

14. Zanon LB; Palharini EM. A química no ensino fundamental de ciências. Revista Química Nova na Escola. 1995; (2): 15 - 18.

15. Ramos LBC; Rosa PRS. O ensino de ciências: fatores intrínsecos e extrínsecos que limitam a realização de atividades experimentais pelo professor dos anos iniciais do ensino fundamental. Investigação em Ensino de Ciências. 2008: 13(3): 299 - 331.

16. Araújo MFS. Trajetória de implementação de uma política pública de formação continuada de professores alfabetizadores: o PNAIC. In: BRASIL. Pacto Nacional pela Alfabetização na Idade Certa - Interdisciplinaridade no ciclo de alfabetização, Secretaria de Educação Básica, Diretoria de Apoio à Gestão Básica, Brasília: MEC/SEB, 2015.

17. Ministério da Educação (BR). Plano Nacional de Formação de Professores da Educação Básica PARFOR. Brasilia(DF): Ministério da Educação; 2012..

18. Toti MCS. O currículo de ciências no ciclo de alfabetização e o efeito do Pacto Nacional pela Alfabetização na Idade Certa (PNAIC): um estudo sobre um município no sudoeste goiano [dissertação] Jataí (GO); 2015. $181 \mathrm{f}$.

19. Rebelo IS; Martins IP; Pedrosa MA. Formação Contínua de Professores para uma Orientação CTS do Ensino de Química: Um Estudo de Caso. Revista Química Nova na Escola. 2008: (27): $30-33,2008$.

20. Bevilacqua GD.; Coutinho-Silva R. O ensino de ciências na $5^{a}$ série através da experimentação. Ciências \& Cognição. 2007: 10: 84-92.

21 Silva JCM. Formação continuada dos professores: visando a própria experiência para uma nova perspectiva. Revista Ibero-americana de Educação. 2011 (55/3): 1--11.

22. Ducatti-Silva KC. A formação no curso de Pedagogia para o ensino de ciências nas séries iniciais. 2005. [Dissertação] Marília (SP): 2005.

23. Silva VF; Bastos F. Formação de Professores de Ciências: reflexões sobre a formação continuada. Alexandria: Revista de Educação em Ciência e Tecnologia. 2012 5(2): 150 - 188.

24. Wenzel JS; Zanon LB; Maldaner AO. A constituição do professor pesquisador pela luta apropriação dos instrumentos culturais do fazer pesquisa. In: Echeverría AR; Zanon LB. Formação Superior em Química no Brasil. Ijuí: Ed. Unijuí, 2010. 